UDC 616.9: 616-036.22

DOI: 10.21668/health.risk/2019.4.14.eng

\title{
INFLUENCE EXERTED BY BIOLOGICAL AND SOCIAL RISK FACTORS ON MORBIDITY WITH TICK-BORNE ENCEPHALITIS IN SOME REGINS IN THE URALS FEDERAL DISTRICT
}

\author{
V.A. Mishchenko ${ }^{1,2,}$ I.A. Kshnyasev ${ }^{2}$, Yu.A. Zakharova ${ }^{1}$, I.P. Bykov', \\ A.G. Sergeev ${ }^{1,3}$, T.A. Rupysheva ${ }^{1}$, L.G. Vyatkina ${ }^{1}$, O.V. Ladygin ${ }^{1}$ \\ ${ }^{1}$ Yekaterinburg Scientific Research Institute for Viral Infections, 23 Letnyaya Str., Yekaterinburg, 620030, \\ Russian Federation \\ ${ }^{2}$ Institute of Plant and Animal Ecology of the Urals Department of Russian Academy of Science, 2028 Marta Str., \\ URAN, Yekaterinburg, 620144, Russian Federation \\ ${ }^{3}$ Ural State Medical University, 3 Repina Str., 630028, Yekaterinburg, Russian Federation
}

Tick-borne encephalitis (TBE) as an infectious disease remains a significant issue in the Urals Federal District (the UFD). To correctly describe impacts exerted by risk factors on TBE epidemic process, it is necessary to analyze both common and individual peculiarities related to how TBE epidemic process develops on endemic administrative territories.

We assessed impacts exerted by biological and social factors on morbidity with TBE in four endemic regions in the UFD (Sverdlovsk, Chelyabinsk, Tyumen, and Kurgan regions) over 2007-2017.

To quantitatively assess contributions made by specific factors into morbidity with TBE, we calculated chances for people who suffered tick bites to fall ill with TBE; it allowed us to apply standard procedures within generalized linear models theory (GLM), namely logistic regression. Our analysis included aggregated data on quantity of people who were bitten by ticks and fell will with TBE in all the examined regions. We also assessed data for each specific region as all these endemic territories had both common and specific regularities related to TBE endemic process development.

We showed statistically significant impacts exerted by specific manageable risk factors (vaccination, immune prevention, and acaricide treatment performed on a territory) on a possibility of TBE occurrence among people bitten by ticks on endemic territories. The examined UFD regions differ as per effects produced by natural and social risk factors on TBE development. Mass vaccine prevention is a key factor in the control over morbidity with the disease.

Risk-oriented approach provides significant additional data for analyzing an epidemiological situation and planning efficient preventive activities in TBE natural foci.

Key words: tick-borne encephalitis, the Urals federal District, logistic regression, morbidity, odds ratio, natural and social risk factors, statistical modeling, specific prevention.

(c) Mishchenko V.A., Kshnyasev I.A., Zakharova Yu.A., Bykov I.P., Sergeev A.G., Rupysheva T.A., Vyatkina L.G., Ladygin O.V., 2019

Vladimir A. Mishchenko - Researcher, Acting Head of the Laboratory for Vector-borne Viral Infections and Tick-borne Encephalitis, The First Category Engineer at the Evolutionary Ecology Laboratory (e-mail: innamoramento23@yandex.ru; tel.: +7 (343) 261-99-47; ORCID: https://orcid.org/0000-0003-4280-283X).

Ivan A. Kshnyasev - Candidate of Biology Sciences, Senior Researcher at the Population Ecology Laboratory (e-mail: kia@ipae.uran.ru; tel.: + 7 (343) 210-38-58; ORCID: https://orcid.org/0000-0002-6281-7644).

Julia A. Zakharova - Doctor of Medical Sciences, Associate Professor, Deputy Director responsible for Research (e-mail: z.y.alexandrovna@mail.ru; tel.: +7 (343) 261-99-47; ORCID: https://orcid.org/0000-0003-3416-0902).

Ivan P. Bykov - Candidate of Medical Sciences, Senior Researcher at the Laboratory for Vector-borne Viral Infections and Tick-borne Encephalitis (e-mail: i.p.bykov@mail.ru; tel.: +7 (343) 261-99-47; ORCID: https://orcid.org/00000002-5157-646X).

Alexandr G. Sergeev - Doctor of Medical Sciences, Professor, Head of Microbiology, Virology and Immunology Department, Head of the Department for Indication and Diagnosis of Viral Infections, Chief Researcher (e-mail: aldr131250@yandex.ru; tel.: +7 (343) 214-86-95; tel.: +7(343)261-99-47; ORCID: https://orcid.org/0000-0002-5784-8673).

Ludmila G. Vyatkina - Medical Statistician at the Urals and Siberian Scientific Methodological HAI Centre (e-mail: vyatkina lg@eniivi.ru; tel.: +7 (343) 261-99-47; ORCID: https://orcid.org/0000-0002-1944-3827).

Tatyana A. Rupysheva - Biologist at the Urals and Siberian Scientific Methodological HAI Centre (e-mail: rupysheva_ta@eniivi.ru; tel.: +7 (343) 261-99-47; ORCID: https://orcid.org/0000-0001-7771-1191).

Oleg V. Ladygin - Head of the Disinfectant and Decontamination Equipment Test Laboratory (e-mail: alibabey@mail.ru; tel.: +7 (343) 261-99-47; ORCID: https://orcid.org/0000-0002-4613-1415). 
Domestic and foreign scientists have managed to achieve excellent results in examining epidemic processes occurring in natural foci infections and their determinants. Despite that, tick-borne encephalitis (TBE) is a still persisting transmissible infection transmitted by ticks.

48 out of 85 regions in the Russian Federation (RF) are endemic as per TBE [1]. The Urals Federal District remains a territory where the situation with TBE is the worst as most administrative regions included into it have high morbidity with TBE among their population. Over the last years the structure of this morbidity has been changing as large foci have occurred due to urban population being infected; the endemic process has been involving new groups of employable population [2]. TBE has ceased to be a solely occupational disease which was typical for workers with specific (forest-related) occupations [3].

Endemic regions located on huge areas in Russia and intra-regional foci differ both as per cyclic nature of morbidity and a risk for population to catch TBE virus. It makes it necessary to work out a differentiated approach to determining administrative territories and a set of anti-epidemic activities [4].

TBE epidemic process is a complicated and multifactor phenomenon. There are several factors that are conventionally considered to determine morbidity with TBE: they are number of ticks, dynamics in number of ticksfeeding animals, spread of contamination among carriers, vaccination scopes, efficiency of immune prevention and acaricide treatments, changes in the structure of reservoir animals, as well as climatic and heliogeophysical (solar activity) conditions [5-10].

Correct description of impacts exerted on TBE epidemic process by the abovementioned factors as well as by any other unaccounted ones requires analyzing general and regional regularities in epidemic process development for endemic administrative territories [11].
Our research goal was to assess effects produced by natural and social risk factors on morbidity with TBE in Sverdlovsk, Chelyabinsk, Tyumen, and Kurgan regions in 2007-2017.

Data and methods. We analyzed morbidity with TBE among people living in Sverdlovsk, Chelyabinsk, Tyumen (without autonomous areas), and Kurgan regions in 2007-2017 basing on data taken from the Form No. 2 of the State Statistical Reports which is called "Data on infectious and parasitic diseases"1. We also analyzed data from annual reports issued by Rospotrebnadzor regional offices over the same period on sanitary-epidemiologic welfare of the population, specifically: people applying for medical aid after they had been bitten by ticks; number of vaccinated and revaccinated people and people who were injected with antitick immunoglobulin as emergency prevention. We assessed a share of infected ticks as well as data on acaricide treatment scopes in the examined regions.

In order to quantitatively assess contributions made by specific risk factors into morbidity with TBE, we calculated what chances there were for people who had been bitten by ticks to fall sick with TBE. These chances were a ratio of a number of sick people $\left(N_{1}\right)$ to the overall number of people who had been bitten but didn't fall sick after it $\left(N_{0}\right)$. It allowed us to apply such a standard tool of generalized linear models (GLM) [12] as logit regression:

$$
\operatorname{Ln}\left(N_{1} / N_{0}\right)=b_{0}+\Sigma b_{i} X_{i}
$$

We assessed effects produced by the following predictors $\left(X_{i}\right)$ : a region (Sverdlovsk, Chelyabinsk, Tyumen, or Kurgan region); number of vaccinated and revaccinated people; a per cent of people who were injected with anti-tick immunoglobulin; a share of infected ticks in natural populations; and an area where there were acaricide treatments against the overall territory of a region (в \%о). Uninterrupted variables which were measured with

\footnotetext{
${ }^{1}$ Form No. 2 "Data on infectious and parasitic diseases". Medicine \& Practice: Practical application of regulatory documents in public healthcare. Available at: http: //mpraktik.ru/forma-2-svedeniya-ob-infekcionnyx-i-parazitarnyx-zabolevaniyax/ (date of visit June 18, 2019).
} 
different scales were standardized (we centered them with a mean value and standardized with standard deviation). As a result, all uninterrupted variables were reduced to a more convenient dimensionless scale. A zero value at the transformed scale corresponded to a simple mean in an initial data series. And here a free member in a regression equation became interpreted and gave a possibility to estimate an expected value of a dependent variable when all the predictors were equal to zero (to mean values for uninterrupted signs).

Odds ratios $(O R)$ and their confidence intervals $(95 \% \mathrm{CI})$ were given after the following transformation: $O R=\exp \left(b_{i}\right)$ or $O R=$ $=1 / \exp \left(b_{i}\right)$, where $b_{i}$ are logit regression parameters (odds ratio logarithms).

As both common and individual regularities related to TBE epidemic process development are typical for endemic territories, we needed to raise statistic reliability of logit regression results; to do that, we jointly analyzed data on the examined regions as well as gave results for each specific one.

We statistically processed and visualized all the obtained results with "Statistica v. 10.0" applied software (StatSoft, Ink) and the statistical medium R (v. 3.4.4) [13].

Results and discussion. We created statistical models showing TBE probability for people who had been bitten by ticks with multiple logit regression. It allowed us to estimate a specific effect produced by each factor together with performing control over effects produced by other predictors. Overall, almost all effects turned out to be statistically significant for four regions in the Urals Federal District (UFD), namely, Sverdlovsk, Chelyabinsk, Tyumen, and Kurgan region, excluding only a share of ticks infected with TBE (Table 1).

Prevailing predictors (risk factors given with descending significance) are the following: "Acaricide treatments"; "Number of vaccinated and revaccinated people"; "A share of bitten people who were injected with Ig". When a square where acaricide treatments took place increased by a standard deviation ( $0.19 \%$ from the overall territory of a region), a person who had been bitten by a tick ran 1.4 times lower risk to fall sick with TBE (confidence interval (CI): 1.26-1.45) (Figure 1-D). If a number of vaccinated and revaccinated people grew by 308 thousand people (one standard deviation), a person who had been bitten by a tick ran 1.21 times lower risk to have TBE (CI: 1.18-1.25). Should a number of vaccinated and revaccinated people exceed one million, chances to get TBE would decrease by 2 times on the examined territory, CI (CI): 1.78-2.18 (Table 1 and Figure 1-A).

Provided that a number of people who were provided with emergency immune prevention increased by $21 \%$ (a limit of one standard deviation), chances to get TBE would fall by 1.2 times with CI: $1.16-1.25$ (Table 1 and Figure 1-B). Overall, our calculations revealed that a share of ticks infected with TBE didn't exert any significant impacts on TBE probability on all the examined territories (totally).

Table 1

Assessing impacts exerted by risk factors on TBE probability for people bitten by ticks in the UFD in 2007-2017 (logit regression: $L R(4)=767.24 ; p<0.0001$ )

\begin{tabular}{|c|c|c|c|c|c|c|c|}
\hline \multirow{3}{*}{ Predictor } & \multirow{3}{*}{$\begin{array}{c}b \\
\mathbf{- 5 . 0 0}\end{array}$} & \multirow{3}{*}{$\begin{array}{c}S E(b) \\
\mathbf{0 . 0 2}\end{array}$} & \multirow{3}{*}{$\begin{array}{c}\text { Z-Wald } \\
\text { statistics } \\
\mathbf{- 3 2 2 . 4 8} \\
\end{array}$} & \multirow{3}{*}{$\begin{array}{l}p \text {-value } \\
<\mathbf{0 . 0 0 0 1}\end{array}$} & \multicolumn{3}{|c|}{ Odds ratio } \\
\hline & & & & & \multirow{2}{*}{$\begin{array}{c}O R \\
- \\
\end{array}$} & \multicolumn{2}{|c|}{$95 \% C I$} \\
\hline & & & & & & - & - \\
\hline \multirow{2}{*}{ Кол-во $V$ и $R V$} & \multirow{2}{*}{-0.19} & \multirow{2}{*}{0.01} & \multirow{2}{*}{-13.42} & \multirow{2}{*}{$<0.0001$} & 1.21 & 1.18 & 1.25 \\
\hline & & & & & $1.94 \AA$ & $1.78 \AA$ & $2.18 \AA$ \\
\hline$\%$ people who got Ig & -0.18 & 0.02 & -10.35 & $<0.0001$ & 1.20 & 1.16 & 1.25 \\
\hline A share of TBE-infected ticks & 0.01 & 0.02 & 0.91 & 0.37 & 1.02 & 0.98 & 1.05 \\
\hline Acaricide treatments (\%o) & -0.34 & 0.02 & -19.41 & $<0.0001$ & 1.40 & 1.36 & 1.45 \\
\hline
\end{tabular}

$\mathrm{N}$ o t e $: b_{0}$ is a free member; $V$ is a number of vaccinated people, $R V$, revaccinated; ${ }^{\circledR}$ - odds ratio, when $V$ and $R V$ quantity grows by 3.5 standard deviations (provided that more than 1 million people are vaccinated); $L R(d f)$ likelihood ratio test, with degrees of freedom number being equal to a number of factor in a model 

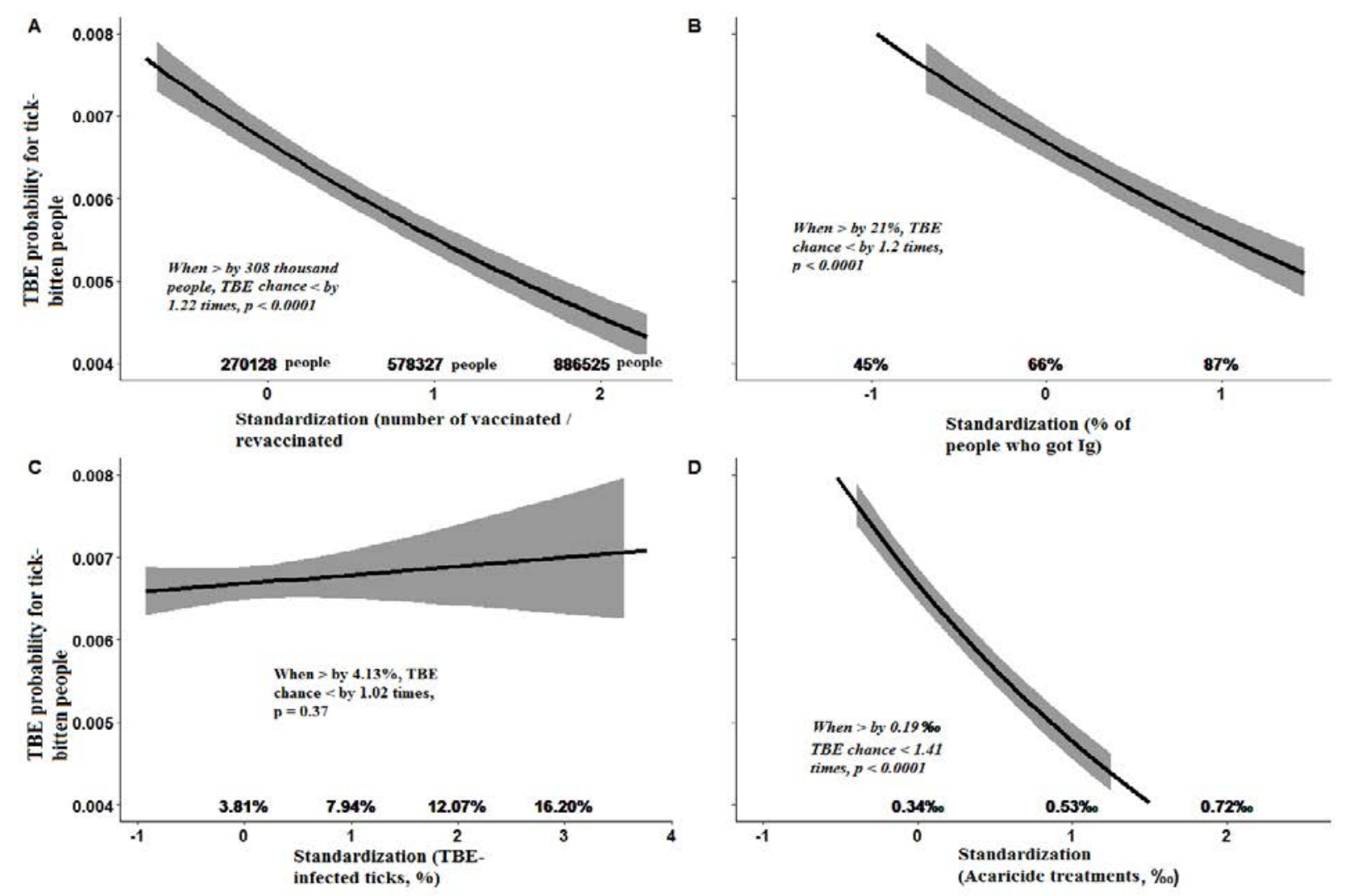

Figure 1. Impacts exerted by risk factors on TBE occurrence among tick-bitten people in the UFD regions in 2007-2017

We created statistical models for an epidemiologic situation in a specific region and revealed that TBE probability for people living in Sverdlovsk region who had been bitten by ticks was substantially associated with vaccination and acaricide treatments scopes. Should squares exposed to acaricide treatments increase by one standard deviation $(0.1 \%$ of the overall region territory); than a chance that the disease occurred would go down by 1.26 times (CI: 1.20-1.33; Table 2 and Figure 2-D). Should a number of people vaccinated against TBE grow by 141 thousand, TBE probability would go down by 1.09 times (Figure 2-A). Should a number of vaccinated people increase up to 1 million people (more than by two standard deviations), TBE probability would decrease by 1.19 times (Table 2).

In Chelyabinsk region, similar to Sverdlovsk region, vaccination and acaricide treatments scopes were the primary factors influencing TBE probability. We should note that the said predictors had a more apparent positive effect. Thus, if a number of people who had been vaccinated and revaccinated increased by 23 thousand people (Figure 3-A), TBE probability dropped by 1.2 times. Should a number of vaccinated people reach 210 thousand people (two standard deviations), a share of those who fell sick with TBE would decrease by 1.44 times. If squares exposed to acaricide treatments increased by $0.15 \%$, TBE probability would fall by 1.32 times (Table 2, Figure 3-D).

The situation existing in Tyumen region was rather opposite to those in Sverdlovsk and Chelyabinsk regions. As per our calculations, we determined that a share of infected ticks and emergency immune prevention were the primary predictors there. Vaccination and acaricide treatments didn't exert any statistically significant impacts on a growth or fall in TBE probability. Over 11 years a number of vaccinated people in Tyumen region was several times lower than in Sverdlovsk and Chelyabinsk regions (68 thousand people against 780 and 164 thousand accordingly). Probably, it was this fact that determined ab- 
sence of any statistically significant effects produced by vaccination on TBE probability on this territory (Table 2, Figure 4-A). A wide scope of emergency immune prevention is quite typical for Tyumen region as on average over 11 years $93 \%$ people who had been bitten by ticks got injected with anti-tick Ig. Should this figure grow by $4 \%$ (one standard deviation and a probable limit for the predictor effect to level out when it has been reached), TBE probability in Tyumen region would go down further by 1.1 times. Average share of infected ticks amounted to $2.77 \%$ (data collected in 2007-2017); a further increase in the parameter by $1.37 \%$ would result in a 1.13 time growth in number of people sick with TBE (Table 2, Figure 4-C).
In Kurgan region the existing situation is the most adverse at present as regards morbidity with TBE. Average long-term morbidity (per 100 thousand people) is 1.3-2.6 times higher than in other regions $(7.82 \% 0000)$. As per predictive estimates only effects produced by acaricide treatments can influence morbidity with TBE and somehow reduce it. Should squares exposed to such treatments increase by $0.05 \%$, TBE probability would go down by 1.6 times (Table 2, Figure 5-D). A share of infected ticks which was $6.44 \%$ on average over 11 years was also the highest in Kurgan region. Should there be a rise in a share of infected ticks by $4.23 \%$, we can expect a 1.13-time growth in number of people who fall sick with TBE (Figure 5-C).

Table 2

Assessment of impacts exerted by risk factors on TBE probability for people bitten by ticks in four UFD regions in 2007-2017 (logit regression)

\begin{tabular}{|c|c|c|c|c|c|c|c|}
\hline \multirow{2}{*}{ Predictor } & \multirow{2}{*}{$b$} & \multirow{2}{*}{$S E(b)$} & \multirow{2}{*}{ Z-Wald statistics } & \multirow{2}{*}{$p$-values } & \multicolumn{3}{|c|}{ Odds ratio } \\
\hline & & & & & OR & $95 \%$ & $6 C$ \\
\hline \multicolumn{8}{|c|}{ Sverdlovsk region; LR $(4)=83.52 ; p<0.0001$} \\
\hline$b_{0}$ & -5.39 & 0.02 & -216.06 & $<0.0001$ & - & - & - \\
\hline \multirow{2}{*}{ Number of $V$ and $R V$} & \multirow{2}{*}{-0.09} & \multirow{2}{*}{$\mathbf{0 . 0 3}$} & \multirow{2}{*}{-3.08} & \multirow{2}{*}{0.002} & 1.09 & $\mathbf{1 . 0 3}$ & 1.15 \\
\hline & & & & & $1.19 \AA$ & $1.06 \AA$ & $1.32 \AA$ \\
\hline \% of bitten people who got Ig & 0.02 & 0.03 & 0.88 & 0.38 & 1.03 & 0.97 & 1.08 \\
\hline A share of infected ticks & 0.03 & 0.03 & 0.97 & 0.33 & 1.03 & 0.97 & 1.08 \\
\hline Acaricide treatments (\%o) & -0.23 & 0.03 & -8.87 & $<0.0001$ & 1.26 & 1.20 & 1.33 \\
\hline \multicolumn{8}{|c|}{ Chelyabinsk region; LR (4) $=60.68 ; p<0.0001$} \\
\hline$b_{0}$ & -5.29 & $\mathbf{0 . 0 3}$ & -170.72 & $<0.0001$ & - & - & - \\
\hline \multirow{2}{*}{ Number of $V$ and $R V$} & \multirow{2}{*}{-0.18} & \multirow{2}{*}{0.04} & \multirow{2}{*}{-4.59} & \multirow{2}{*}{$<0.0001$} & 1.20 & 1.11 & 1.30 \\
\hline & & & & & $1.44 \AA$ & $1.12 ®$ & $1.69 \AA$ \\
\hline$\%$ of bitten people who got Ig & 0.003 & 0.05 & 0.06 & 0.95 & 1.00 & 0.91 & 1.11 \\
\hline A share of infected ticks & 0.02 & 0.04 & 0.52 & 0.60 & 1.02 & 0.94 & 1.10 \\
\hline Acaricide treatments (\%o) & -0.28 & 0.06 & -4.31 & $<0.0001$ & 1.32 & 1.16 & $\mathbf{1 . 5 0}$ \\
\hline \multicolumn{8}{|c|}{ Tyumen region; LR $(4)=46.07 ; p<0.0001$} \\
\hline$b_{0}$ & -5.11 & $\mathbf{0 . 0 3}$ & $-\mathbf{1 4 8 . 8 6}$ & $<0.0001$ & - & - & - \\
\hline Number of $V$ and $R V$ & -0.15 & 0.10 & -1.44 & 0.15 & 1.16 & 0.95 & 1.41 \\
\hline$\%$ of bitten people who got Ig & -0.10 & $\mathbf{0 . 0 5}$ & -2.11 & 0.04 & 1.10 & 1.01 & 1.20 \\
\hline A share of infected ticks & 0.12 & 0.04 & 3.13 & 0.002 & 1.13 & $\mathbf{1 . 0 5}$ & 1.22 \\
\hline Acaricide treatments (\%o) & -0.01 & 0.10 & -0.05 & 0.96 & 1.01 & 0.83 & 1.23 \\
\hline \multicolumn{8}{|c|}{ Kurgan region; $\operatorname{LR}(4)=125.81 ; p<0.0001$} \\
\hline$b_{0}$ & -4.36 & 0.04 & $-\mathbf{1 0 0 . 0 7}$ & $<0.0001$ & - & - & - \\
\hline Number of $V$ and $R V$ & 0.18 & 0.06 & 2.85 & 0.004 & 1.20 & 1.06 & 1.36 \\
\hline$\%$ of bitten people who got Ig & 0.11 & 0.04 & 2.62 & 0.01 & 1.12 & $\mathbf{1 . 0 3}$ & 1.21 \\
\hline A share of infected ticks & 0.12 & 0.05 & 2.59 & 0.01 & 1.13 & $\mathbf{1 . 0 3}$ & 1.23 \\
\hline Acaricide treatments (\%o) & -0.47 & 0.05 & -9.39 & $<0.0001$ & 1.59 & 1.45 & 1.77 \\
\hline
\end{tabular}

$\mathrm{N}$ o t e $: b_{0}$ is a free member; $V$ means vaccinated people, $R V$ means revaccinated; ${ }^{\circledR}$ - odds ratio, when $V$ and $R V$ quantity grows by 2 standard deviations (provided that more than 1 million people are vaccinated); $L R(d f)$ likelihood ratio test, with degrees of freedom number being equal to a number of factor in a model 

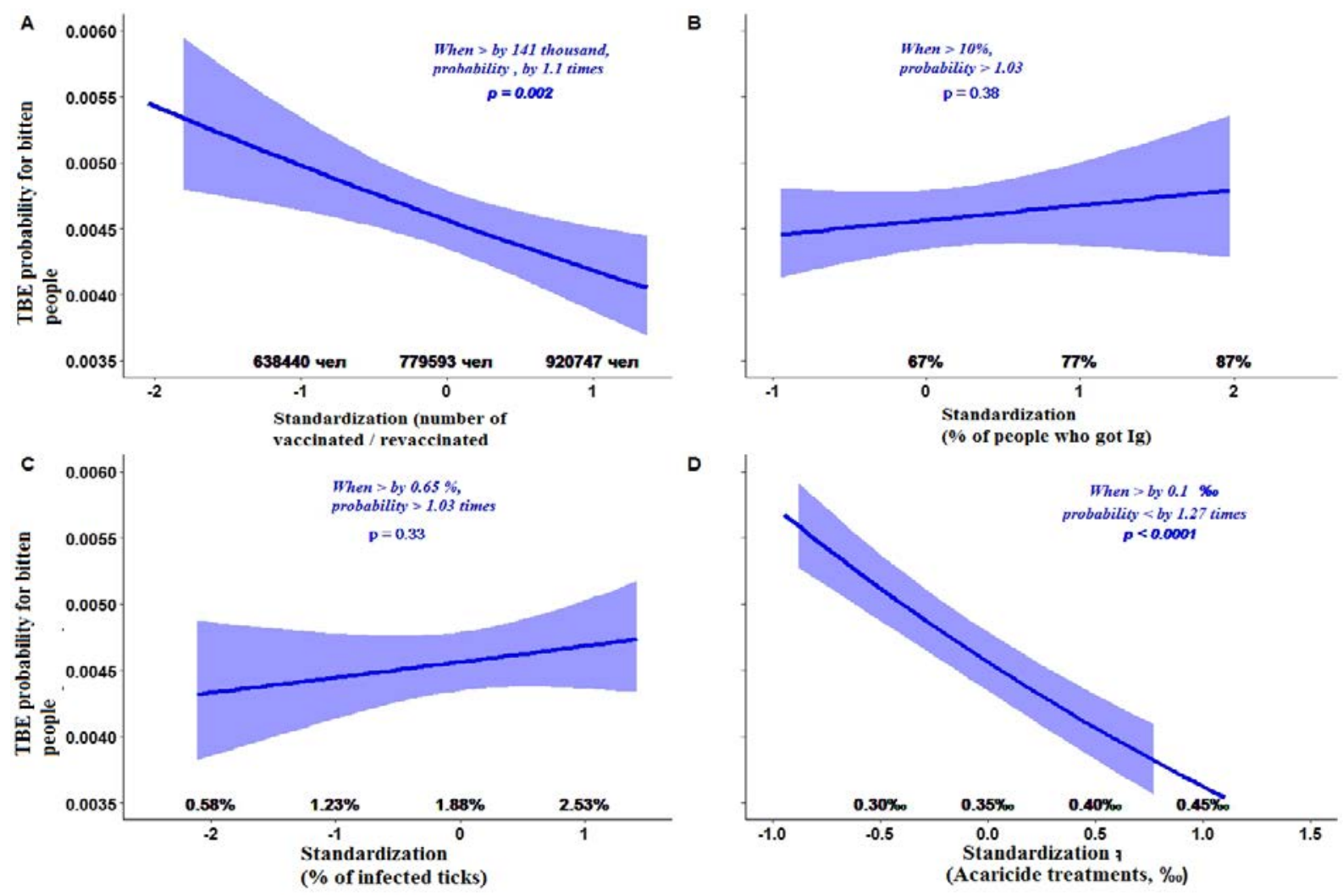

Figure 2. Impacts exerted by risk factors on TBE occurrence among people bitten by ticks in Sverdlovsk region in 2007-2017
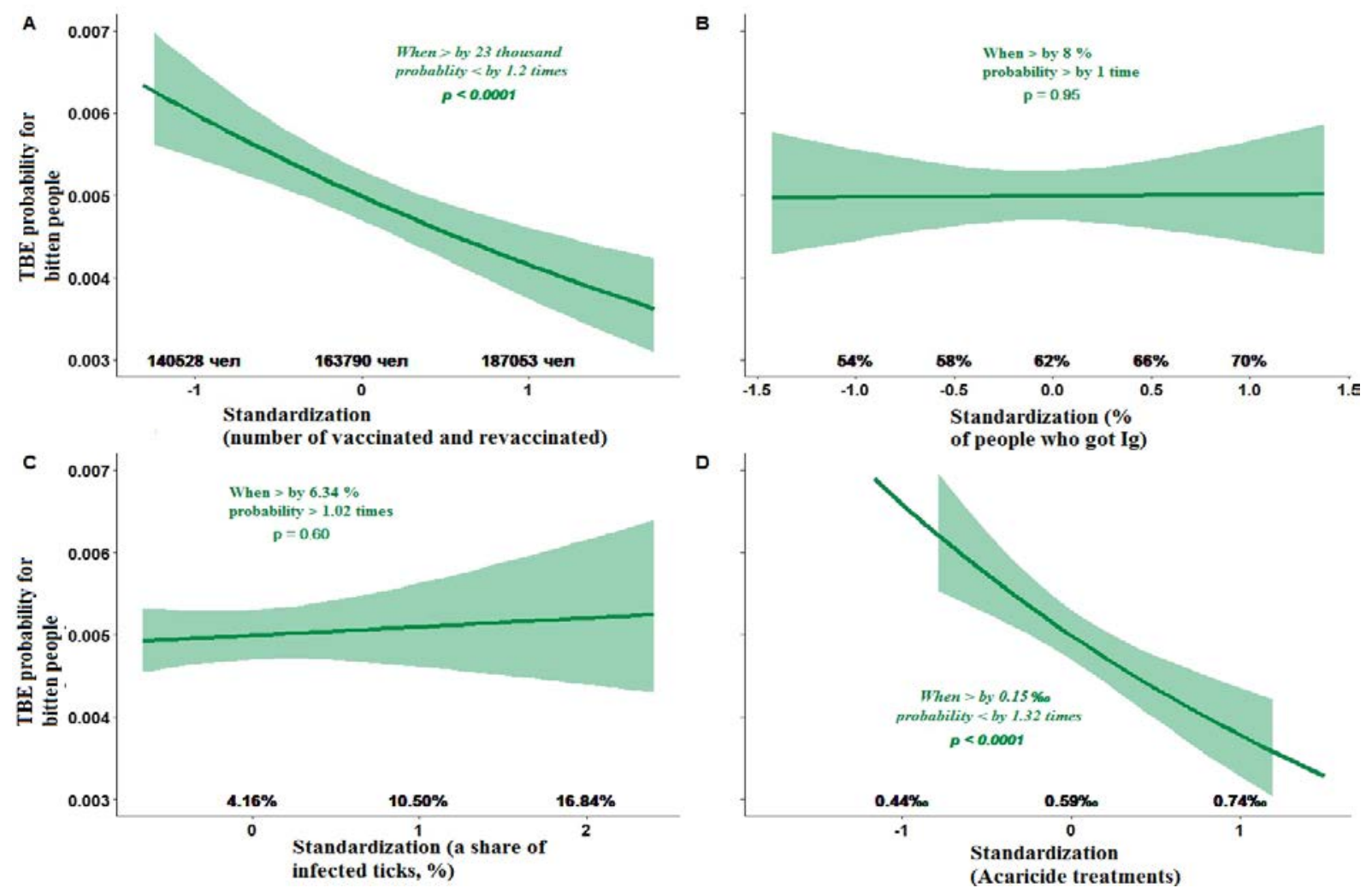

Figure 3. Impacts exerted by risk factors on TBE occurrence among people bitten by ticks in Chelyabinsk region in 2007-2017 

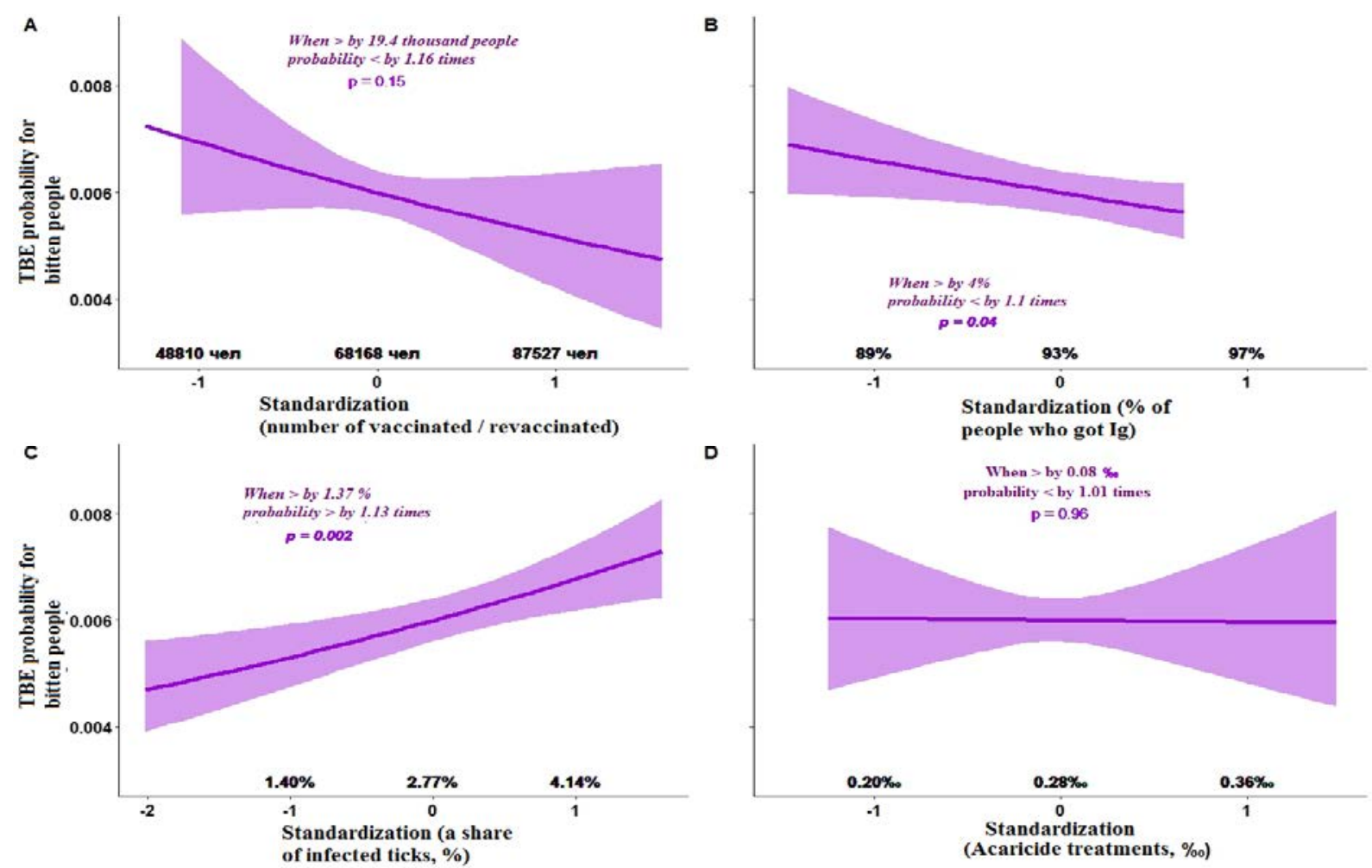

Figure 4. Impacts exerted by risk factors on TBE occurrence among people bitten by ticks in Tyumen region in 2007-2017
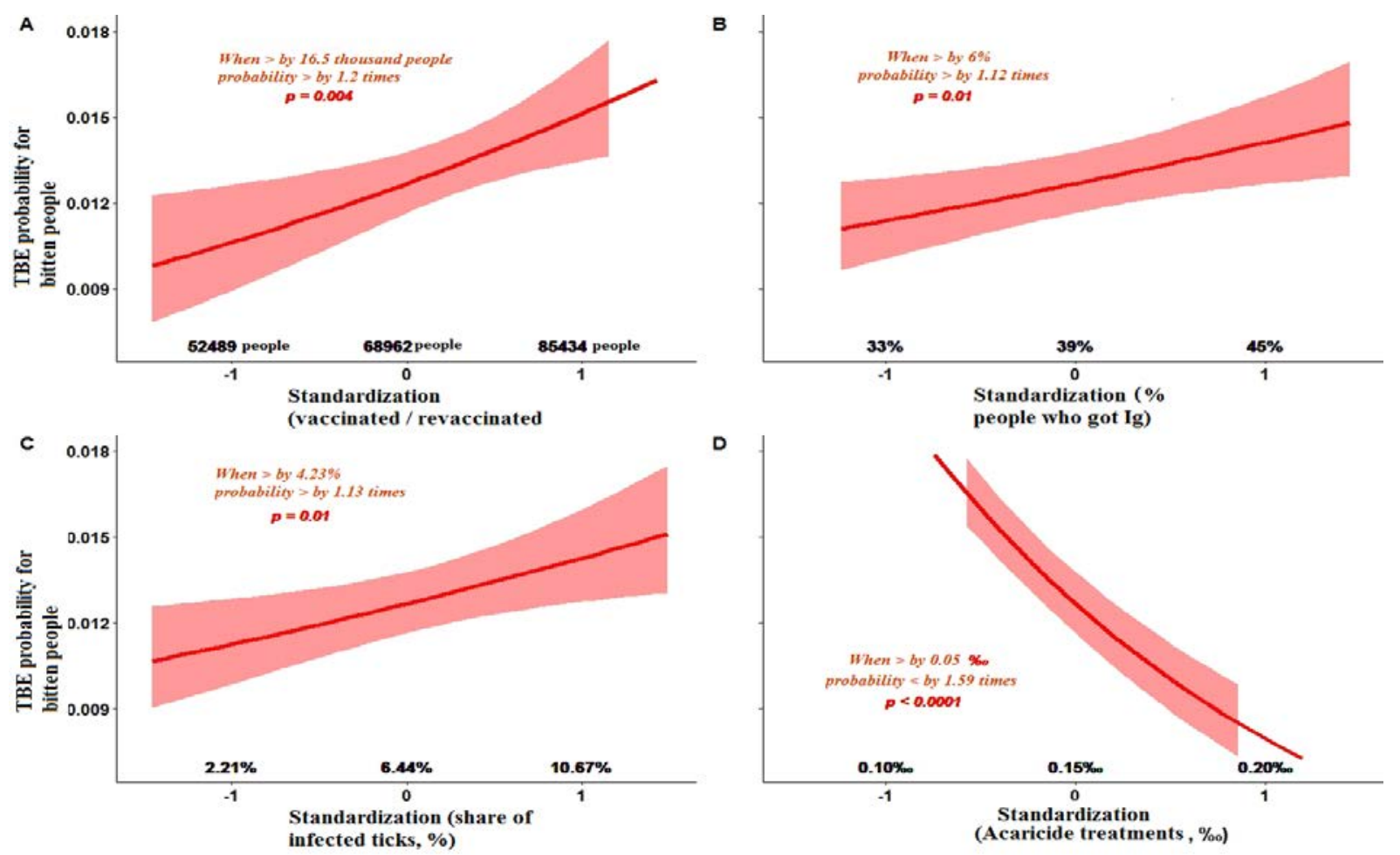

Figure 4. Impacts exerted by risk factors on TBE occurrence among people bitten by ticks in Kurgan region in 2007-2017 
As regards such factors as vaccination and emergency immune prevention, logit regression results revealed a rather paradox situation that existed in Kurgan region. When there was an increase in number of vaccinated people and people provided with immune prevention, TBE probability also grew (Figure 5-A, B). However, we should note that a number of vaccinated people and immune preventions scopes were the lowest in Kurgan region over the examined 11-year period.

Therefore, the examined regions in the UFD differ in terms of effects produced by natural and social risk factors on TBE occurrence.

In Sverdlovsk and Chelyabinsk regions mass immunization program for population has been implemented since 2009 and 2012 accordingly and it is a key component in the system of measured aimed at preventing the disease; it influences epidemiologic process substantially [14].

Despite emergency prevention is also implemented in wide scopes in Sverdlovsk region, according to our calculations it doesn't have any significant effects on TBE probability, and it requires further and more profound investigation.

L.I. Volkova et al. [15] also revealed that emergency prevention was inefficient in Sverdlovsk region. They determined that only active immunization provided for population in an endemic region would allow achieving a substantial decrease in morbidity with TBE $[15,16]$.

Significant effects produced by acaricide treatments on TBE occurrence are most likely to be indirectly caused by their influence on infection carriers (ticks). Nevertheless, it is well known that it is rather difficult to estimate contribution made by these prevention activities into a fall in morbidity with TBE. Squares exposed to acaricide treatments are substantially smaller that the square of a whole region; besides, such treatments are usually accomplished in places specifically designed for people's rest (forest camps, for example) and people usually get infected beyond such places [17].

Literature data and long-term observations allow concluding that immune prevention against TBE in Tyumen region is accomplished in a scope that is one of the highest in Russia and it obviously indicates that results of laboratory examinations performed on ticks removed off bitten people are not taken into account when immunoglobulin is prescribed [18].

A significant effect produced by a share of infected ticks in morbidity in Tyumen and Kurgan regions is, in our opinion, caused by two basic reasons: population living in steppe and forest-steppe zones contact ticks more frequently (people who fall sick pare predominantly from rural areas). Several species of infections carriers (ticks) are typical for southern steppe and forest-steppe zones in Tyumen and Kurgan regions (Ixodes and Dermacentor families). Periods when a lot of people apply for medical aid as they have been bitten by ticks are determined by female ticks from both families being extremely active. Ticks from Dermacentor family are an additional TBE vector; they are more numerous and their seasonal activity is longer and it can make for a growth in a share of infected Ixodes [19, 20].

In Kurgan region on average over 11 years only 69 thousand people were vaccinated and it amounted to $7.6 \%$ of the overall region population; probably, insufficient vaccination and small scopes of immune prevention (only $39 \%$ of all the people who had been bitten by ticks got immunoglobulin) [20] result in annual high morbidity with the disease among population and, consequently, in a growth in a share of people who fall sick after being bitten by ticks ${ }^{2}$. Low number of population vaccinated against the disease and violations in accomplishing official vaccination schemes can lead to a decrease in immunity against TBE in the nearest future and make effects produced by vaccination more remote [21].

\footnotetext{
${ }^{2}$ The Order by the deputy to the Chief Sanitary Inspector in Kurgan region "On enhancing surveillance over diseases caught from tick in Kurgan region" No. 71 dated April 22, 2016. Available at: http://www.45.rospotrebnadzor.ru/rss_all//asset_publisher/Kq6J/content/id/470206 (date of visit June 18, 2019).
} 


\section{Conclusions:}

1. We created a common logit regression model to assess effects produced by risk factors on TBE probability for people bitten by ticks in four regions located in the UFD. The model revealed statistically significant influence exerted by such manageable factors as vaccination, immune prevention, and acaricide treatments. Mass vaccination provided for population in these regions is a key component in control over morbidity with TBE.

2. The examined regions located in UFD are different regarding contributions made by risk factors into morbidity with TBE. In Sverdlovsk and Chelyabinsk regions primary impacts on any changes in TBE probability are exerted by vaccination and acaricide treatments. In Tyumen region primary factors are high scopes of emergency immune prevention and a share of infected ticks in natural foci. In
Kurgan region the existing situation regarding morbidity with TBE is rather adverse and it is caused by insufficient vaccination and immune prevention as well as by a high share of infected ticks and infection carriers (ticks) being highly active.

3. Our analysis of social and biological factors in UFD regions with different morbidity indicates it is truly vital to implement a risk-oriented approach for planning efficient prevention activities.

Funding. The research was accomplished within the scientific and research work project "Molecular epidemiology of tick-borne encephalitis virus on various territories in the Urals Federal District" which is a part of Rospotrebnadzor's Brunch Scientific and Research Program for 2016-2020. (Registration No.: AAAA-A16-116061710033-9).

Conflict of interests. The authors declare there is no any conflict of interests.

\section{References}

1. Chernokhaeva L.L., Kholodilov I.S., Pakskina N.D. Current distribution area of tick-borne encephalitis in the Russian Federation. Meditsinskaya virusologiya, 2016, vol. 30, no. 1, pp. 6-22 (in Russian).

2. Kon'kova-Reidman A.B., Ter-Bagdasaryan L.V. Modern aspects of epidemiology of ticks transmitted infections. Epidemiologiya infektsionnye bolezni, 2014, vol. 19, no. 5, pp. 26-31 (in Russian).

3. Zlobin V.I. Epidemiologic situation and problems in struggle with tick-borne encephalitis in Russian Federation. Terra Medica, 2010, vol. 61, no. 2, pp. 13-21 (in Russian).

4. Yastrebov V.K., Rudakov N.V., Rudakova, S.A. Epidemiology of the transmissible tick-borne infections in Russia. Zdorov'e naseleniya i sreda obitaniya, 2016, vol. 284, no. 11, pp. 8-12 (in Russian).

5. Zhigalsky O.A. The Analysis of Forecasting Methods of Morbidity from Zoonotic Infections. Epidemiologiya i vaktsinoprofilaktika, 2012, vol. 64, no. 3, pp. 26-31 (in Russian).

6. Shchuchinova L.D., Zlobin V.I. The social factors influencing tick-borne encephalitis incidence in the Altai Republic. Sibirskii meditsinskii zhurnal, 2014, vol. 124, no. 1, pp. 78-80 (in Russian).

7. Lbov G.S., Polyakova G.L., Bakhvalova V.N., Morozova O.V. The Role of The Climatic Factors in Tick-Born Encephalitis Disease's Indices. Vestnik Novosibirskogo gosudarstvennogo universiteta. Seriya: Biologiya, klinicheskaya meditsina, 2010, vol. 8, no. 2, pp. 33-39 (in Russian).

8. Berikov V.B., Lbov G.S., Polyakova G.L., Bakhvalova V.N., Panov V.V., Shchuchinova L.D., Gladky P.A., Korotkov Yu.S. [et al.]. Analysis of Factors Influencing the Incidence of Tick-Borne Encephalitis, Using Logical-and-Probabilistic and Correlation-Regression Models. Epidemiologiya $i$ vaktsinoprofilaktika, 2011, vol. 61, no. 6, pp. 25-34 (in Russian).

9. Knap N., Avšič-Županc T. Factors affecting the ecology of tick-borne encephalitis in Slovenia. Epidemiology and Infection, 2015, vol. 143, no. 10, pp. 2059-2067. DOI: 10.1017/S0950268815000485

10. Kiffner C., Zucchini W., Schomaker P., Vor T., Hagedorn P., Niedrig M., Rühe F. Determinants of tick-borne encephalitis in counties of southern Germany, 2001-2008. International Journal of Health Geographics, 2010, vol. 9, pp. 1-10. DOI: 10.1186/1476-072X-9-42

11. Tyulko Zh.S., Yakimenko V.V., Rudakov N.V., Savelyev D.A., Andaev E.I., Balakhonov S.V. Determination of tick-borne encephalitis morbidity risk in the Russian Federation based on discriminant analysis of long-term observations. Natsional'nye prioritety Rossii, 2017, vol. 26, no. 4, pp. 54-59 (in Russian). 
12. McCullagh P., Nelder J.A. Generalized linear models. London, Chapman and Hall Publ., 1989, 511 p.

13. R Development Core Team. R: a language and environment for statistical computing. Vienna, Austria, The R Foundation for Statistical Computing Publ., 2018. Available at: https://www.R-project.org (21.03.2019).

14. Luchinina S.V., Semenov A.I., Stepanova O.N., Pogodina V.V., Gerasimov S.G., Shcherbinina M.S., Kolesnikova L.I., Suslova T.A. Vaccinal prevention of Tick-Borne Encephalitis in Chelyabinsk Region: Dynamics of Vaccination, population Immunity, Analysis of TBE cases in Vaccinated persons. Epidemiologiya $i$ vaktsinoprofilaktika, 2016, vol. 15, no. 1 (86), pp. 67-76 (in Russian).

15. Volkova L.I., Kovtun O.P., Romanenko V.V., Ankudinova M.V., Ankudinova A.V. Clinical efficiency of vaccination and passive immunization against tick borne encephalitis in middle Urals. Ural'skii meditsinskii zhurnal, 2009, vol. 56, no. 2, pp. 129-134 (in Russian).

16. Kunz C. TBE vaccination and the Austrian experience. Vaccine, 2003, vol. 21, no. 1, pp. 50-55. DOI: $10.1016 / \mathrm{s} 0264-410 x(02) 00813-7$

17. Potsikailo O.V., Nikitin A. Ya., Noskov A.K., Romanova T.G., Kurganov V.E., Viktorova T.N., Kopylova I.A., Botvinkin A.D. Present-Day Peculiarities of Epidemiology and Prophylaxis Results of Tick-Borne Encephalitis in the Republic of Khakassia. Epidemiologiya $i$ vaktsinoprofilaktika, 2018, vol. 17, no. 1 (98), pp. 48-55 (in Russian).

18. Nikitin A.Y., Andaev E.I., Noskov A.K., Pakskina N.D., Yatsmenko E.V., Verigina E.V., Balakhonov S.V. Peculiarities of the Epidemiological Situation on Tick-Borne Viral Encephalitis in the Russian Federation in 2017 and the Forecast for 2018. Problemy osobo opasnykh infektsii, 2018, no. 1, pp. 44-49 (in Russian).

19. Shchuchinova L.D., Kozlova I.V., Zlobin V.I. Leading Role of Dermacentor Ticks in Maintenance of the Natural Foci of Tick-Borne Encephalitis in the Altai Republic. Epidemiologiya $i$ vaktsinoprofilaktika, 2013, vol. 73, no. 6, pp. 16-20 (in Russian).

20. Pogodina V.V., Shcherbinina M.S., Skrynnik S.M., Bochkova N.G., Kolyasnikova N.M., Shirokova N.A. Epidemiological Situation of Tick-Borne Encephalitis in the Kurgan Region (1983-2017). Epidemiologiya i vaktsinoprofilaktika, 2018, vol. 17, no. 4 (101), pp. 46-55 (in Russian).

21. Shcherbinina M.S., Pogodina V.V., Skrynnik S.M., Levina L.S., Bochkova N.G., Gerasimov S.G., Lisenkov A.N., Ishmyhametov A.A. The Condition of Post-Vaccination Immunity to the Tick-Borne Encephalitis Virus in the Population Highly Endemic Area with Siberian Subtype Domination. Epidemiologiya $i$ vaktsinoprofilaktika, 2018, vol. 17, no. 2 (99), pp. 27-36 (in Russian).

Mishchenko V.A.' Kshnyasev I.A., Zakharova Yu.A., Bykov I.P., Sergeev A.G., Rupysheva T.A., Vyatkina L.G., Ladygin O.V. Influence exerted by biological and social risk factors on morbidity with tickborne encephalitis in some regins in the urals federal district. Health Risk Analysis, 2019, no. 4, pp. 129-138. DOI: 10.21668/health.risk/2019.4.14.eng

Received: 30.07 .2019

Accepted: 27.11. 2019

Published: 30.12.2019 